\title{
Sigh in Supine and Prone Position during Acute Respiratory Distress Syndrome
}

\author{
Paolo Pelosi, Nicola Bottino, Davide Chiumello, Pietro Caironi, Mauro Panigada, Chiara Gamberoni, \\ Giorgia Colombo, Luca M. Bigatello, and Luciano Gattinoni \\ Dipartimento di Scienze Cliniche e Biologiche, Università degli Studi dell'Insubria, Ospedale di Circolo, Fondazione Macchi, Varese; Istituto di \\ Anestesia e Rianimazione, Università degli Studi di Milano, Ospedale Maggiore IRCCS, Milano; and Department of Anesthesia and Critical \\ Care, Massachusetts General Hospital, Harvard Medical School, Boston, Massachusetts
}

\begin{abstract}
Interventions aimed at recruiting the lung of patients with acute respiratory distress syndrome (ARDS) are not uniformly effective. Because the prone position increases homogeneity of inflation of the lung, we reasoned that it might enhance its potential for recruitment. We ventilated 10 patients with early ARDS $\left(\mathrm{Pa}_{\mathrm{O}_{2}} / \mathrm{F}_{\mathrm{O}_{2}}, 121 \pm\right.$ $46 \mathrm{~mm} \mathrm{Hg}$; positive end-expiratory pressure, $14 \pm 3 \mathrm{~cm} \mathrm{H}_{2} \mathrm{O}$ ) in supine and prone, with and without the addition of three consecutive "sighs" per minute to recruit the lung. Inspired oxygen fraction, positive end-expiratory pressure, and minute ventilation were kept constant. Sighs increased $\mathrm{Pa}_{\mathrm{O}_{2}}$ in both supine and prone $(\mathrm{p}<0.01)$. The highest values of $\mathrm{Pa}_{\mathrm{O}_{2}}(192 \pm 41 \mathrm{~mm} \mathrm{Hg})$ and end-expiratory lung volume $(1,840 \pm 790 \mathrm{ml})$ occurred with the addition of sighs in prone and remained significantly elevated 1 hour after discontinuation of the sighs. The increase in $\mathrm{Pa}_{\mathrm{O}_{2}}$ associated with the sighs, both in supine and prone, correlated linearly with the respective increase of end-expiratory lung volume $(r=0.82, p<0.001)$. We conclude that adding a recruitment maneuver such as cyclical sighs during ventilation in the prone position may provide optimal lung recruitment in the early stage of ARDS.
\end{abstract}

Keywords: acute lung injury; acute respiratory distress syndrome; mechanical ventilation; recruitment; end-expiratory lung volume

Mechanical ventilation with low tidal volume may prevent ventilator-induced lung injury (VILI) and increased survival of patients with acute lung injury/acute respiratory distress syndrome (ALI/ARDS) (1). However, using low ventilatory volumes may also limit alveolar inflation and promote atelectasis and hypoxemia $(2,3)$. Thus, "lung protective" strategies to ventilate patients with ALI/ARDS have to consider two potentially conflicting goals: preventing VILI and reinflating collapsed alveoli.

Lung inflation can be promoted with a recruitment maneuver (RM), which consists in periodically raising the alveolar pressure above the level reached during tidal ventilation. RMs are commonly performed by applying a sustained pressure of $40-50 \mathrm{~cm} \mathrm{H}_{2} \mathrm{O}$ at the airway for 30-60 seconds (4). Alternatively, one or more large breaths (sighs) of 40-50 cm $\mathrm{H}_{2} \mathrm{O}$ plateau airway pressure can be delivered cyclically during tidal ventilation (5). RMs improve gas exchange and respiratory mechanics in a number of patients but are not uniformly effective $(6,7)$. Reasons for the inconsistent results of RMs include the following: (1) the concomitant use of

(Received in original form March 13, 2002; accepted in final form November 27, 2002) Correspondence and requests for reprints should be addressed to Luciano Gattinoni, Istituto di Anestesia e Rianimazione, Università degli Studi di Milano, Ospedale Maggiore-IRCCS, via Francesco Sforza 35, 20122 Milano, Italy. E-mail: gattinon@polic.cilea.it

This article has an online supplement, which is accessible from this issue's table of contents online at www.atsjournals.org

Am J Respir Crit Care Med Vol 167. pp 521-527, 2003

Originally Published in Press as DOI: 10.1164/rccm.200203-1980C on December 18, 2002 Internet address: www.atsjournals.org high positive end-expiratory pressure (PEEP), which per se promotes recruitment $(8,9)$, and $(2)$ an inhomogeneous distribution of lung collapse/edema, which results in a preferential inflation of already open (thus more compliant) areas of the lung rather than of the targeted collapsed alveoli (8). Because the distribution of lung inflation and collapse in early ALI/ARDS are often inhomogeneous $(10,11)$, we reasoned that if we could reverse or decrease this inhomogeneity, we might enhance the effects of a RM.

A way to achieve a more even distribution of lung inflation in patients with ALI/ARDS is to ventilate them prone. Turning from supine to prone reverses in part their characteristic distribution of lung collapse and edema that has most consolidation in the dorsal, dependent areas of the lung and sufficient aeration in the ventral regions (12). This more favorable distribution of lung inflation improves gas exchange and respiratory mechanics in a number of patients with ALI/ARDS (13-15).

Hence, we designed this study of patients with early ARDS to test the hypothesis that prone position enhances the physiologic effect of a RM. Our hypothesis is supported by the findings of a canine model of ALI showing that a lower PEEP is required in the prone than in the supine position to preserve the effects of a RM (16). Our hypothesis is clinically relevant because approximately $50 \%$ of ARDS patients do not exhibit a satisfactory response to a RM in the supine position $(6,7)$.

\section{METHODS}

\section{Study Population}

The study was approved by our Institutional Review Board. Informed consent was obtained from the patients' next of kin. We studied 10 consecutive patients in the early phase of ALI/ARDS, defined according to the criteria of the American European Consensus Conference (17). We excluded patients with known chronic obstructive lung disease.

\section{Study Design}

All patients were sedated with fentanyl (1.5-5 $\mu \mathrm{g} / \mathrm{kg} / \mathrm{hour})$ and diazepam $(0.03-0.18 \mathrm{mg} / \mathrm{kg} / \mathrm{hour})$, paralyzed with pancuronium $(0.05-0.1 \mathrm{mg} /$ $\mathrm{kg}$ /hour), and ventilated in the volume control mode with a Siemens Servo ventilator $300 \mathrm{C}$ (Siemens, Solna, Sweden). All had indwelling arterial and pulmonary artery catheters. The study included the following periods: baseline supine ( 2 hours), sighs in supine (1 hour), second baseline supine (1 hour), baseline prone ( 2 hours), sigh in prone ( 1 hour), and second baseline prone (1 hour). Measurements were taken at the end of each period, and the entire study lasted approximately 8 hours. Patients were positioned prone as previously described (14).

Mechanical ventilation was provided using a tidal volume of approximately $7 \mathrm{ml} / \mathrm{kg}$ of actual body weight to maintain an upper limit of plateau airway pressure of approximately $35 \mathrm{~cm} \mathrm{H}_{2} \mathrm{O}$. A slight increase in airway pressure $\left(2-3 \mathrm{~cm} \mathrm{H}_{2} \mathrm{O}\right)$ was accepted in the prone position because it was associated with a decreased compliance of the chest wall and was not deemed to reflect an increase in transpulmonary pressure. The level of PEEP was selected by the attending physician using a PEEP trial that is routinely performed in ALI/ARDS patients in our 
TABLE 1. PATIENT CHARACTERISTICS

\begin{tabular}{|c|c|c|c|c|c|c|c|c|}
\hline Patient No. & $\begin{array}{c}\text { Sex } \\
(M / F)\end{array}$ & $\begin{array}{l}\text { Age } \\
(Y r s)\end{array}$ & $\begin{array}{c}\text { BMI } \\
\left(k g / m^{2}\right)\end{array}$ & $\begin{array}{l}\mathrm{Pa}_{\mathrm{O}_{2}} / \mathrm{Fl}_{\mathrm{O}_{2}} \\
(m m \mathrm{Hg})\end{array}$ & $\begin{array}{c}\text { PEEP } \\
\left(\mathrm{cm} \mathrm{H} \mathrm{H}_{2} \mathrm{O}\right)\end{array}$ & $\begin{array}{c}\text { Days of } \\
\text { ALI/ARDS }\end{array}$ & Diagnosis & $\begin{array}{l}\text { Outcome } \\
(S / D)\end{array}$ \\
\hline 1 & M & 46 & 23 & 51 & 15 & 3 & Infectious pneumonia & $S$ \\
\hline 2 & $\mathrm{~F}$ & 65 & 27 & 70 & 20 & 5 & Infectious pneumonia & $\mathrm{D}$ \\
\hline 3 & M & 79 & 28 & 85 & 10 & 2 & Infectious pneumonia & $\mathrm{D}$ \\
\hline 4 & $\mathrm{~F}$ & 64 & 33 & 193 & 10 & 4 & Peritonitis & $\mathrm{D}$ \\
\hline 5 & M & 53 & 27 & 154 & 15 & 2 & Infectious pneumonia & $S$ \\
\hline 6 & M & 62 & 28 & 101 & 15 & 3 & Infectious pneumonia & $S$ \\
\hline 7 & M & 69 & 26 & 182 & 15 & 3 & Fournier's gangrene & $S$ \\
\hline 8 & M & 71 & 26 & 137 & 15 & 2 & Haemorrhagic shock, peritonitis & $\mathrm{D}$ \\
\hline 9 & $\mathrm{~F}$ & 61 & 23 & 132 & 10 & 2 & Infectious pneumonia & $\mathrm{S}$ \\
\hline 10 & $\mathrm{M}$ & 64 & 27 & 117 & 15 & 3 & Peritonitis & $S$ \\
\hline Mean \pm SD & $7 \mathrm{M} / 3 \mathrm{~F}$ & $63 \pm 9$ & $27 \pm 3$ & $121 \pm 46$ & $14 \pm 3$ & $3 \pm 1$ & & $6 \mathrm{~S} / 4 \mathrm{D}$ \\
\hline
\end{tabular}

Definition of abbreviations: ALI/ARDS = acute lung injury/acute respiratory distress syndrome; BMI = body mass index; D = dead; Days of ARDS = days elapsed from the time when ARDS criteria were met and the time of the study; PEEP = positive end-expiratory pressure; $S=$ survivor.

unit (5). Intrinsic PEEP was measured by an occlusion maneuver at end expiration.

\section{Sighs}

Sighs were provided using a dedicated software program that was set to deliver three consecutive volume-limited breaths per minute with a plateau airway pressure of $45 \mathrm{~cm} \mathrm{H}_{2} \mathrm{O}$ (5). The number of no-sigh breaths was automatically reduced to maintain a constant minute ventilation.

\section{Measurements}

The end-expiratory lung volume (EELV) was measured using a simplified closed circuit helium dilution method described previously (18).

Mean airway pressure was calculated as the area under the curve of the airway pressure over time trace. The "weighted" mean airway pressure measures the mean airway pressure of both sigh and nonsigh breaths during the sigh periods. Both mean and weighted mean were calculated digitally by a waveform analysis software (Colligo; Elekton, Milan, Italy). Respiratory mechanics were obtained with a standard method during an end-inspiratory pause maneuver (14).

\section{Statistical Analysis}

Data presented are mean $\pm \mathrm{SD}$. We used a two-factor univariate analysis of variance (ANOVA) for repeated measures to test the effect of the factors position (supine and prone) and treatment (sighs) within patients. When ANOVA was significant, we performed a post hoc comparison between each time and Baseline 1. In addition, we compared each data point in supine position with the correspondent data point in prone position. All of these comparisons were performed with the pairwise Bonferroni $t$ test. The least-square method was used for linear regression analysis. A p value of less than 0.05 was considered statistically significant. The software Sigma Stat 2.03 (SPPS, Inc., Chicago, IL) was used for statistical analysis.

\section{RESULTS}

The general characteristics of the study population are reported in Table 1.

\section{Gas Exchange}

Ventilatory parameters during the various study periods are reported in Table 2 . By design, the $\mathrm{FI}_{\mathrm{O}_{2}}(0.80 \pm 0.15), \operatorname{PEEP}(14 \pm$ $\left.3 \mathrm{~cm} \mathrm{H}_{2} \mathrm{O}\right)$, and minute ventilation were maintained constant throughout the study. Also constant was the mean airway pressure of the nonsigh breaths so that the weighted mean airway pressure increased slightly with the sighs. No intrinsic PEEP was detected.

Gas exchange and EELV during the various study periods are reported in Table 3 . Adding the sighs in the supine position increased the $\mathrm{Pa}_{\mathrm{O}_{2}}$ from $95 \pm 26$ to $110 \pm 31 \mathrm{~mm} \mathrm{Hg}(\mathrm{p}<0.01)$, decreased venous admixture from $38.2 \pm 9.5$ to $34.5 \pm 10.8 \%$ $(\mathrm{p}<0.01)$, and did not change EELV significantly $(1,400 \pm 640$ to $1,470 \pm 680 \mathrm{ml}, \mathrm{p}=0.1)$. The $\mathrm{Pa}_{\mathrm{CO}_{2}}$ showed a decreasing trend in both positions ( $\mathrm{p}<0.05$ by ANOVA, treatment). The physiologic dead space ( $\left.\mathrm{VD}_{\mathrm{D}} / \mathrm{V}_{\mathrm{T}}\right)$ did not change throughout the study. After discontinuing the sighs, $\mathrm{Pa}_{\mathrm{O}_{2}}$, venous admixture, and EELV returned to baseline.

Changing from the supine to the prone position increased the $\mathrm{Pa}_{\mathrm{O}_{2}}$ from $95 \pm 26$ to $155 \pm 30 \mathrm{~mm} \mathrm{Hg}(\mathrm{p}<0.01)$, decreased venous admixture from $38.2 \pm 9.5$ to $30 \pm 9.3 \%(\mathrm{p}<0.01)$, and increased EELV from $1,400 \pm 640$ to $1,570 \pm 720 \mathrm{ml}(\mathrm{p}<0.01)$ Adding the sighs in the prone position increased $\mathrm{Pa}_{\mathrm{O}_{2}}(155 \pm$ 30 to $192 \pm 41 \mathrm{~mm} \mathrm{Hg}, \mathrm{p}<0.01)$, decreased venous admixture $(30 \pm 9.3$ to $25.2 \pm 10 \%, \mathrm{p}<0.01)$, and increased EELV $(1,570 \pm$ 720 to $1,840 \pm 790 \mathrm{ml}, \mathrm{p}<0.01)$ compared with the prone position without sighs. After discontinuing the sighs, $\mathrm{Pa}_{\mathrm{O}_{2}}$ and EELV decreased but remained significantly greater than before adding the sighs. The individual patient's response to the addition of the sighs in the supine and prone positions is shown in Figure 1.

Adding the sighs increased the $\mathrm{Pa}_{\mathrm{O}_{2}}$ more in prone than in supine ( $37 \pm 17$ vs. $16 \pm 11 \mathrm{~mm} \mathrm{Hg}, \mathrm{p}<0.001)$. It also increased the EELV more in prone than in supine $(277 \pm 198$ vs. $68 \pm$ $83 \mathrm{ml}, \mathrm{p}<0.01)$. The increase of $\mathrm{Pa}_{\mathrm{O}_{2}}$ associated with the sighs in prone correlated linearly with the increase of $\mathrm{Pa}_{\mathrm{O}_{2}}$ associated with the sighs in supine $(r=0.77, \mathrm{p}<0.01$; Figure 2$)$. Also, the increase in EELV associated with the sighs in prone correlated linearly with the increase in EELV associated with the sighs in supine $(r=0.65, \mathrm{p}<0.05)$. The changes in $\mathrm{Pa}_{\mathrm{O}_{2}}$ that occurred when turning from supine to prone did not correlate with changes in $\operatorname{EELV}(r=0.31, \mathrm{p}=\mathrm{NS})$. However, changes in $\mathrm{Pa}_{\mathrm{O}_{2}}$ that occurred with adding the sighs both in the supine and prone position correlated with changes in $\operatorname{EELV}(r=0.82, \mathrm{p}<0.0001$; Figure 3).

\section{Respiratory Mechanics}

Changes in static elastance of the respiratory system, partitioned into its lung and chest wall components, are reported in Table 4. The addition of the sighs decreased the elastance of the respiratory system in both supine $\left(30 \pm 16\right.$ vs. $33 \pm 15 \mathrm{~cm} \mathrm{H}_{2} \mathrm{O} / \mathrm{L}, \mathrm{p}<$ $0.05)$ and prone position $\left(32 \pm 13\right.$ vs. $35 \pm 15 \mathrm{~cm} \mathrm{H}_{2} \mathrm{O} / \mathrm{L}, \mathrm{p}<$ $0.05)$. The elastance of the lung showed a decreasing trend with the addition of the sighs in both positions $(p<0.05$ by ANOVA, treatment). It also showed a decreasing trend as an effect of the prone position ( $\mathrm{p}<0.05$ by ANOVA, position). Turning from supine to prone increased the static elastance of the chest wall from $10 \pm 5$ to $18 \pm 7 \mathrm{~cm} \mathrm{H}_{2} \mathrm{O} / \mathrm{L}(\mathrm{p}<0.01)$. 


\begin{tabular}{|c|c|c|c|c|c|c|}
\hline & \multicolumn{3}{|c|}{ Supine } & \multicolumn{3}{|c|}{ Prone } \\
\hline & Baseline 1 & Sigh & Baseline 2 & Baseline 1 & Sigh & Baseline 2 \\
\hline \multicolumn{7}{|l|}{ Non-sigh breaths } \\
\hline Tidal volume, $\mathrm{ml}$ & $590 \pm 138$ & $611 \pm 142$ & $598 \pm 136$ & $614 \pm 59$ & $621 \pm 160$ & $614 \pm 148$ \\
\hline Respiratory rate, breaths/min & $14 \pm 2$ & $10 \pm 3^{*}$ & $14 \pm 2$ & $14 \pm 2$ & $10 \pm 3^{*}$ & $14 \pm 2$ \\
\hline $\mathrm{T} \mathrm{I} / \mathrm{T}_{\text {tot }}$ & $0.4 \pm 0.1$ & $0.4 \pm 0.1$ & $0.4 \pm 0.1$ & $0.4 \pm 0.1$ & $0.4 \pm 0.1$ & $0.4 \pm 0.1$ \\
\hline Plateau airway pressure, $\mathrm{cm} \mathrm{H}_{2} \mathrm{O}$ & $32 \pm 4$ & $31 \pm 5$ & $32 \pm 5$ & $34 \pm 4^{\dagger}$ & $33 \pm 3$ & $34 \pm 3$ \\
\hline Mean airway pressure, $\mathrm{cm} \mathrm{H} \mathrm{H}_{2} \mathrm{O}$ & $20 \pm 3$ & $20 \pm 3$ & $20 \pm 3$ & $21 \pm 2$ & $21 \pm 2$ & $21 \pm 3$ \\
\hline Minute ventilation, L/min & $8.5 \pm 1.8$ & $6.0 \pm 1.7$ & $8.7 \pm 1.9$ & $8.8 \pm 2.0$ & $6.0 \pm 1.4$ & $8.8 \pm 1.8$ \\
\hline \multicolumn{7}{|l|}{ Sigh breaths } \\
\hline Tidal volume, $\mathrm{ml}$ & - & $947 \pm 321$ & - & - & $963 \pm 335$ & - \\
\hline Respiratory rate, breaths/min & - & $3 \pm 0$ & - & - & $3 \pm 0$ & - \\
\hline $\mathrm{T} \mathrm{I} / \mathrm{T}_{\text {tot }}$ & - & $0.4 \pm 0.1$ & - & - & $0.4 \pm 0.1$ & - \\
\hline Plateau airway pressure, $\mathrm{cm} \mathrm{H}_{2} \mathrm{O}$ & - & $44 \pm 2$ & - & - & $45 \pm 2$ & - \\
\hline Mean airway pressure, $\mathrm{cm} \mathrm{H}_{2} \mathrm{O}$ & - & $23 \pm 3$ & - & - & $23 \pm 3$ & - \\
\hline Minute ventilation, L/min & - & $2.8 \pm 1.0$ & - & - & $2.9 \pm 1.0$ & - \\
\hline \multicolumn{7}{|l|}{ Overall } \\
\hline Weighted mean airway pressure, $\mathrm{cm} \mathrm{H}_{2} \mathrm{O}$ & $20 \pm 3$ & $21 \pm 3^{*}$ & $20 \pm 3$ & $21 \pm 2$ & $22 \pm 2$ & $21 \pm 3$ \\
\hline Respiratory rate, breaths/min & $14 \pm 2$ & $13 \pm 3$ & $14 \pm 2$ & $14 \pm 2$ & $13 \pm 3$ & $14 \pm 2$ \\
\hline Minute ventilation, L/min & $8.5 \pm 1.8$ & $8.9 \pm 2.1$ & $8.7 \pm 1.9$ & $8.8 \pm 2.0$ & $8.9 \pm 2.0$ & $8.8 \pm 1.8$ \\
\hline
\end{tabular}

Definition of abbreviation: $\mathrm{T}_{\mathrm{I}} / \mathrm{T}_{\text {tot }}=$ inspiratory time over total cycle time.

Data are mean \pm SD.

${ }^{*} p<0.05$ versus baseline.

${ }^{\dagger} p<0.05$ versus supine.

\section{Hemodynamics}

The prone position increased central venous pressure, pulmonary artery pressure, and pulmonary artery occlusion pressures compared with supine (Table 5), without changes in cardiac output and systemic arterial pressure. Adding the sighs in both supine and prone did not affect hemodynamics.

\section{Complications}

No complications were observed with the application of sighs. Specifically, there was no occurrence of detectable barotrauma, such as pneumothorax and interstitial emphysema. No complications were noted with prone ventilation.

\section{DISCUSSION}

The most important findings of our study of patients with early ALI/ARDS are (1) the addition of sighs increased the $\mathrm{Pa}_{\mathrm{O}_{2}}$ in both the supine and prone positions and (2) the increase of $\mathrm{Pa}_{\mathrm{O}_{2}}$ was likely related to lung recruitment.

The use of RMs has been proposed to limit alveolar closure during low tidal volume ventilation in patients with ALI/ARDS
(4). However, as many as $50 \%$ of patients have no significant improvement in gas exchange after 30-120 seconds of sustained inflation at airway pressures of $40-50 \mathrm{~cm} \mathrm{H}_{2} \mathrm{O}(6,7)$. A situation that may limit the efficacy of RMs may occur in early ALI/ ARDS when collapse and edema are preferentially located in the dependent, dorsal areas of the lung (11). In such cases, the pressure applied at the airway with a RM may preferentially distribute to compliant areas of the lung that are already ventilated rather than to the collapsed alveoli that one would like to recruit.

Prone ventilation abolishes the physiologic dorsoventral gradient of lung inflation in animal models $(19,20)$ and can preferentially inflate the collapsed dorsal areas of the lung of patients with early ARDS (12). Thus, prone ventilation may increase the potential of the ARDS lung to be recruited. In a canine model of oleic acid-induced ALI, a 30-second sustained inflation at $60 \mathrm{~cm} \mathrm{H}_{2} \mathrm{O}$ was more effective in the prone than in the supine position, and a lower PEEP was required in prone to maintain the same gas exchange as in supine (16).

In our study of patients with early ALI/ARDS, the $\mathrm{Pa}_{\mathrm{O}_{2}}$ increased with the addition of sighs in the supine position, increased

TABLE 3. GAS EXCHANGE AND END-EXPIRATORY LUNG VOLUME

\begin{tabular}{|c|c|c|c|c|c|c|}
\hline & \multicolumn{3}{|c|}{ Supine } & \multicolumn{3}{|c|}{ Prone } \\
\hline & Baseline 1 & Sigh & Baseline 2 & Baseline 1 & Sigh & Baseline 2 \\
\hline $\mathrm{Pa}_{\mathrm{O}_{2}}, \mathrm{~mm} \mathrm{Hg}$ & $95 \pm 26$ & $110 \pm 31^{\dagger}$ & $97 \pm 32$ & $155 \pm 30^{\ddagger}$ & $192 \pm 41^{\dagger}$ & $176 \pm 37^{\dagger}$ \\
\hline $\mathrm{Pa}_{\mathrm{CO}_{2}}, \mathrm{~mm} \mathrm{Hg}$ & $53 \pm 10$ & $51 \pm 10^{\S}$ & $53 \pm 14$ & $54 \pm 16$ & $51 \pm 15^{\S}$ & $53 \pm 17$ \\
\hline $\mathrm{pH}$ & $7.31 \pm 0.07$ & $7.31 \pm 0.09$ & $7.30 \pm 0.10$ & $7.30 \pm 0.12$ & $7.30 \pm 0.13$ & $7.30 \pm 0.12$ \\
\hline $\mathrm{EELV}, \mathrm{ml}$ & $1,400 \pm 640$ & $1,470 \pm 680$ & $1,360 \pm 640$ & $1,570 \pm 720^{\ddagger}$ & $1,840 \pm 790^{\dagger}$ & $1,770 \pm 750^{\dagger}$ \\
\hline Venous admixture, \% & $38.2 \pm 9.5$ & $34.5 \pm 10.8^{\dagger}$ & $36.7 \pm 12.2$ & $30.0 \pm 9.3^{\ddagger}$ & $25.2 \pm 10.0^{\dagger}$ & $27.8 \pm 10.3^{*}$ \\
\hline $\mathrm{V}_{\mathrm{D}} / \mathrm{V}_{\mathrm{T}}$ & $0.60 \pm 0.10$ & $0.58 \pm 0.10$ & $0.58 \pm 0.12$ & $0.62 \pm 0.15$ & $0.61 \pm 0.16$ & $0.55 \pm 0.17$ \\
\hline
\end{tabular}

Definition of abbreviations: EELV = end-expiratory lung volume; $\mathrm{V}_{\mathrm{D}} / \mathrm{V}_{\mathrm{T}}=$ physiologic dead space, measured in seven patients.

${ }^{*} \mathrm{p}<0.05$ versus baseline.

${ }^{\dagger} \mathrm{p}<0.01$ versus baseline.

${ }^{\ddagger} \mathrm{p}<0.01$ versus supine.

$\S p<0.05$, analysis of variance (effect of "treatment"). 

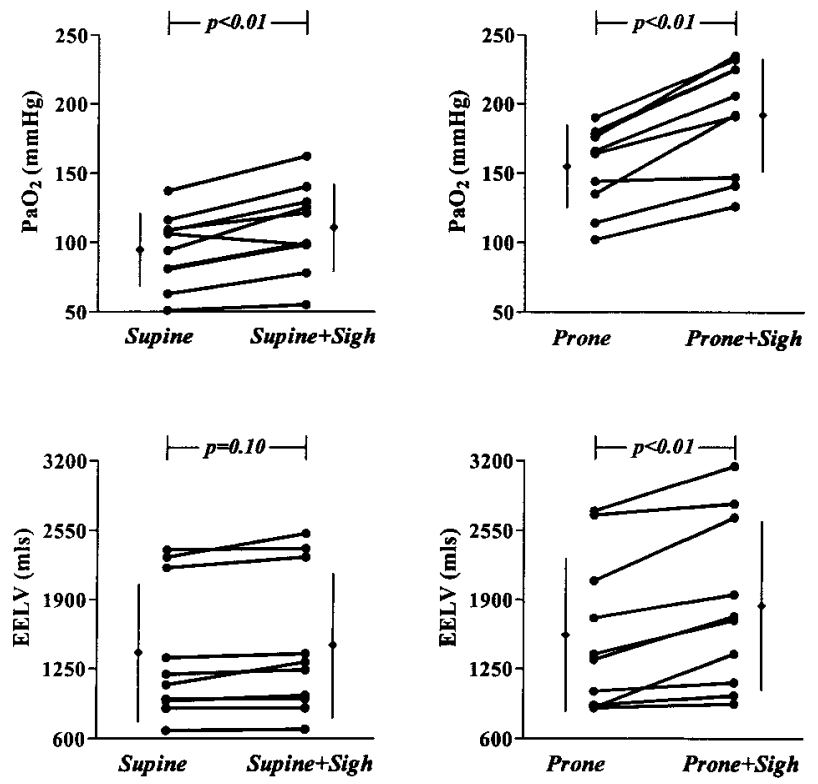

Figure 1. Individual change induced by sighs in the $\mathrm{Pa}_{\mathrm{O}_{2}}$ (upper panel) and EELV (lower panel) in supine (left side) and prone positions (right side). The $p$ values at the top refer to the comparison between the average value before and after the addition of the sighs.

further by turning prone, and further again by adding sighs in the prone position (Table 3). The increase of $\mathrm{Pa}_{\mathrm{O}_{2}}$ associated with sighs during prone ventilation persisted for at least 1 hour after returning to the supine position. These results beg two main questions: (1) How did the sighs increase $\mathrm{Pa}_{\mathrm{O}_{2}}$, and (2) how did the prone position result in a greater effect of the sighs?

\section{How Did the Sighs Increase $\mathrm{Pa}_{\mathrm{O}_{2}}$ ?}

In two other studies of sighs in ARDS, changes of $\mathrm{Pa}_{\mathrm{O}_{2}}$ correlated linearly with the respective changes of $\operatorname{EELV}(5,21)$, suggesting that lung recruitment was responsible for the increase in $\mathrm{Pa}_{\mathrm{O}_{2}}$. Our current results extend that observation to the prone position. Although the effect of sighs on EELV in supine was not as pronounced, the EELV and $\mathrm{Pa}_{\mathrm{O}_{2}}$ increases still correlated linearly $(r=0.71, \mathrm{p}<0.05$; Figure 3$)$. The reason for the smaller effect is unclear. One possibility is that 6 of our 10 patients had ARDS of pulmonary origin (Table 1), which is associated with a lower potential for recruitment $(22,23)$; the three largest in-

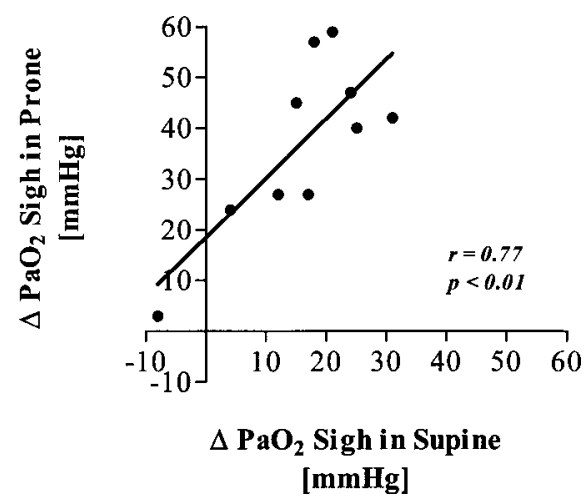

Figure 2. Linear correlation between changes in $\mathrm{Pa}_{\mathrm{O}_{2}}\left(\Delta \mathrm{Pa}_{\mathrm{O}_{2}}\right)$ with sighs in the supine and prone position.

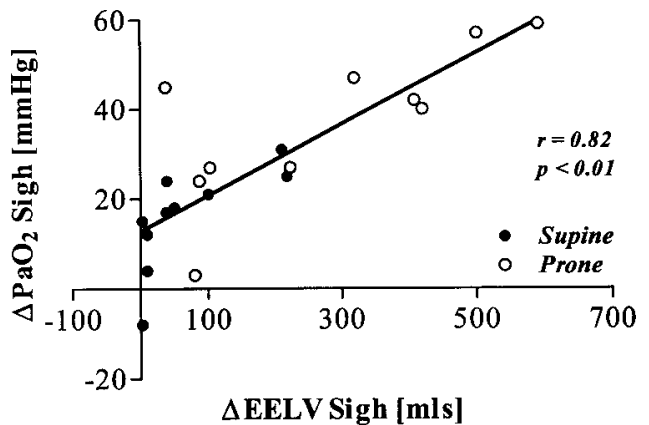

Figure 3. Linear correlation between the changes of $E E L V$ and $\mathrm{Pa}_{\mathrm{O}_{2}}$ when sighs were added to ventilation in the supine (closed circles) and the prone (open circles) position.

creases of EELV occurred in patients with extrapulmonary ARDS (Patients 4, 8, and 10).

What is striking in this study is the response to the sighs in the prone position. Figure 3 shows how the significant correlation between changes in EELV and $\mathrm{Pa}_{\mathrm{O}_{2}}$ is driven by the measurements obtained in prone. It would be tempting to speculate that those patients that for some physiologic reason (e.g., pulmonary etiology of ARDS) are not destined to respond to a RM can benefit exquisitely by proning. However, we did not prospectively select a patient population with the appropriate size and characteristics to address this question.

It can be argued that an increase of the EELV is not synonymous with lung recruitment. Other useful methods to document recruitment include the measurement of ventilation and perfusion with the multiple inert gas elimination technique (9), which, however, is available only in a few specialized centers, and highresolution computed tomography (24). We did not include computed tomography imaging in this study because it would have added further complexity to an already long ( 8 hours) protocol. However, we reasoned that if collapsed lung tissue is reinflated while ventilating with a constant tidal volume, the elastance of the respiratory system will improve. We did document a significant decrease in static elastance of the respiratory system in the nonsigh breaths during ventilation with sighs, in both positions (Table 4), as it has been observed previously $(5,21)$.

Thus, the significant linear correlation between the increase of EELV and $\mathrm{Pa}_{\mathrm{O}_{2}}$ and the decrease in static elastance of the respiratory system strongly suggests that sighs improved gas exchange by promoting lung recruitment.

\section{How Did the Prone Position Enhance the Effect of the Sighs?}

Prone ventilation caused the largest increase in $\mathrm{Pa}_{\mathrm{O}_{2}}$ among the three interventions tested in this study, that is, sighs in supine, the prone position, and sighs in prone. It also increased EELV versus the supine position, but not as markedly as did the subsequent addition of sighs (Table 3). Furthermore, the changes in $\mathrm{Pa}_{\mathrm{O}_{2}}$ and EELV did not correlate $(r=0.35)$ in contrast to what occurred when the sighs were added (Figure 3 ).

Thus, the mechanisms that improve $\mathrm{Pa}_{\mathrm{O}_{2}}$ with a RM (sighs in this case) and with prone ventilation may in part differ. Turning from supine to prone frequently increases $\mathrm{Pa}_{\mathrm{O}_{2}}$ without a clear correlation with the change of $\operatorname{EELV}(14,25)$. Different from PEEP and RMs, the prone position may redistribute rather than globally increase the pressure gradient that determines lung inflation and result in a homogeneous pattern of inflation (12).

Based on these observations, we reasoned that if we ventilate patients with early ALI/ARDS in the prone position, we may 
TABLE 4. MEASUREMENT OF STATIC ELASTANCE (cm $\left.\mathrm{H}_{2} \mathrm{O} / \mathrm{L}\right)$

\begin{tabular}{|c|c|c|c|c|c|c|}
\hline & \multicolumn{3}{|c|}{ Supine } & \multicolumn{3}{|c|}{ Prone } \\
\hline & Baseline 1 & Sigh & Baseline 2 & Baseline 1 & Sigh & Baseline 2 \\
\hline \multicolumn{7}{|l|}{ Non-sigh breaths } \\
\hline Elastance of the respiratory system & $33 \pm 15$ & $30 \pm 16^{*}$ & $33 \pm 16$ & $35 \pm 15$ & $32 \pm 13^{*}$ & $34 \pm 13$ \\
\hline Elastance of the lung & $19 \pm 9$ & $17 \pm 10^{\ddagger}$ & $20 \pm 12$ & $17 \pm 13^{\S}$ & $14 \pm 10^{\ddagger \S}$ & $15 \pm 12^{\S}$ \\
\hline Elastance of the chest wall & $10 \pm 5$ & $10 \pm 4$ & $11 \pm 4$ & $18 \pm 7^{\dagger}$ & $17 \pm 6$ & $18 \pm 6$ \\
\hline \multicolumn{7}{|l|}{ Sigh breaths } \\
\hline Elastance of the respiratory system & - & $36 \pm 16$ & - & - & $37 \pm 18$ & \\
\hline Elastance of the lung & - & $23 \pm 12$ & - & - & $19 \pm 15$ & \\
\hline Elastance of the chest wall & - & $12 \pm 4$ & - & - & $17 \pm 15$ & \\
\hline
\end{tabular}

Data are mean \pm SD. Partitioning of lung and chest wall was obtained in seven patients.

${ }^{*} p<0.05$ versus baseline.

$+\mathrm{p}<0.01$ versus supine.

${ }^{\ddagger} \mathrm{p}<0.05$, analysis of variance (effect of "treatment").

$\S p<0.05$, analysis of variance (effect of "position").

make their lung topography more suitable to recruitment. Our results substantiate this hypothesis. First, our data are in line with previous studies of the prone position in both adults (14) and children (26) that showed a significant increase of $\mathrm{Pa}_{\mathrm{O}_{2}}$ (in our case an average of $60 \mathrm{~mm} \mathrm{Hg}$ ) associated with a modest increase of EELV (approximately $200 \mathrm{ml}$; Table 3). This kind of interaction between $\mathrm{Pa}_{\mathrm{O}_{2}}$ and EELV is typical of the prone position and is likely the result of redistribution of alveolar ventilation. Second, measuring the mechanical properties of the respiratory system provided support to our hypothesis (Table 4). In the face of a significant increase of the chest wall elastance (typical of the prone position), the static elastance of the lung showed a trend toward a decrease throughout the three prone study periods, documented by the statistically significant effect of position by two-way ANOVA. In an earlier study of the prone position, we observed a very similar change of elastance of the lung, which progressed to become significant only after resuming the supine position (14).

One can argue that changes of EELV or the lack thereof do not definitely document or exclude the occurrence of recruitment. Measurement of regional pulmonary inflation would have been ideal, but it is problematic. Regional computed tomography analysis of gas/tissue ratio has been used for this purpose (27, 28 ) but is a complex and not standardized method. A qualitative estimate of the changes associated with turning prone has been repeatedly documented with computed tomography, and we were not compelled to replicate it $(12,24)$.

Thus, the increase of $\mathrm{Pa}_{\mathrm{O}_{2}}$ associated with a limited increase of EELV and the trend toward an improved elastance of the lung suggest that the mechanism responsible for the increased effect of the sighs in the prone position was a more even distribution of lung inflation.

\section{Methodological Considerations}

Sighs. We chose to use sighs as a RM because they maintain recruitment for a period of at least one hour without hemodynamic compromise $(5,21)$. Our results confirm these observations. We chose to deliver three consecutive breaths of $45-\mathrm{cm}$ $\mathrm{H}_{2} \mathrm{O}$ pressure because we have previously shown the efficacy of this design in ALI/ARDS patients (5). Sighs have also been delivered as a single pressure-limited breath with a long (3-5 seconds) inspiratory time during pressure support ventilation (21). As with all RMs, there are uncertainties regarding how often they should be applied, whether they cause any VILI themselves, and how significantly they impact the outcome of patients with ALI/ARDS.

PEEP. We chose to maintain the PEEP set with a standard PEEP trial. However, having not controlled the level of PEEP may have limited the extent of our findings. High PEEP (more than $10 \mathrm{~cm} \mathrm{H}_{2} \mathrm{O}$ ) during ventilation with or without low tidal volume may have associated with better lung recruitment $(3,6$, 8,29 ). Our relatively high level of PEEP may have somewhat hampered the recruiting effect of our sighs.

Tidal volume. Our set tidal volume of approximately $7 \mathrm{ml} /$ $\mathrm{kg}$ of body weight was higher than suggested by the Acute Respiratory Distress Syndrome Network trial $6 \mathrm{ml} / \mathrm{kg}$ of ideal body weight (1). We elected to maintain the tidal volume selected clinically because it reflected common practice (30), even though this relatively large tidal volume may have promoted lung recruitment and possibly blunted the effect of our interventions.

TABLE 5. HEMODYNAMICS

\begin{tabular}{|c|c|c|c|c|c|c|}
\hline & \multicolumn{3}{|c|}{ Supine } & \multicolumn{3}{|c|}{ Prone } \\
\hline & Baseline 1 & Sigh & Baseline 2 & Baseline 1 & Sigh & Baseline 2 \\
\hline Heart rate, beats/min & $107 \pm 14$ & $110 \pm 18$ & $106 \pm 15$ & $109 \pm 18$ & $110 \pm 19$ & $109 \pm 19$ \\
\hline Mean arterial pressure, $\mathrm{mm} \mathrm{Hg}$ & $73 \pm 7$ & $74 \pm 11$ & $74 \pm 11$ & $76 \pm 14$ & $80 \pm 15$ & $79 \pm 15$ \\
\hline Mean pulmonary artery pressure, $\mathrm{mm} \mathrm{Hg}$ & $31 \pm 5$ & $29 \pm 5$ & $3 \pm 5$ & $34 \pm 6^{*}$ & $34 \pm 6$ & $35 \pm 5$ \\
\hline Central venous pressure, $\mathrm{mm} \mathrm{Hg}$ & $13 \pm 2$ & $14 \pm 2$ & $14 \pm 2$ & $16 \pm 4^{*}$ & $16 \pm 4$ & $17 \pm 4$ \\
\hline Pulmonary artery occlusion pressure, $\mathrm{mm} \mathrm{Hg}$ & $15 \pm 2$ & $15 \pm 3$ & $15 \pm 3$ & $18 \pm 5^{\dagger}$ & $17 \pm 5$ & $18 \pm 5$ \\
\hline Cardiac index, $\mathrm{L} / \mathrm{min} / \mathrm{m}^{-2}$ & $4.3 \pm 0.8$ & $4.0 \pm 0.5$ & $4.0 \pm 0.5$ & $4.0 \pm 0.5$ & $4.0 \pm 0.7$ & $3.9 \pm 0.7$ \\
\hline
\end{tabular}

Data are mean \pm SD.

${ }^{*} p<0.05$ versus supine.

${ }^{\dagger} \mathrm{p}<0.01$ versus supine. 
Hemodynamics. The only hemodynamic changes were recorded when turning prone, independently of the sighs. They consisted in a mild increase of central venous pressure and pulmonary artery pressures. We are unable to discern whether these changes reflect true transmural pressures or whether they are secondary to positional changes of the chest and the mediastinal structures. Nevertheless, the mean arterial pressure and cardiac output remained normal, suggesting that no significant hemodynamic event occurred.

Study design. There are possible shortcomings in the way we designed our study.

We enrolled a small number of subjects: 10 patients. Although larger studies can provide more robust data and add details to the results, our small number of subjects yielded statistically significant results of the proposed endpoints and is not unusual for a physiologic study $(9,12,27,28,31)$.

Randomization. Ideally, the interventions tested in a study using subjects as their own control should be randomized. If not, one could argue that, for example, the large increase in $\mathrm{Pa}_{\mathrm{O}_{2}}$ that we detected with our last intervention (sighs in the prone position) could have been determined by the combination of the previous interventions: sighs in supine and prone ventilation. The experimental study of Cakar and colleagues used a randomized design, with a group of animals starting supine and another starting prone (16). However, this design is impractical in critically ill patients. Our inclusion of a second baseline after the sigh periods demonstrated a satisfactory return to baseline of the measured variables, thus excluding a significant cumulative effect of the previous intervention.

Esophageal pressure. Esophageal pressure measurement in critically ill patients has shortcomings, which we discussed in a previous publication (14). Turning prone changes the position of the mediastinum and with that its effect on the pleural pressure measurement, just like on vascular pressures. Despite these limitations, measurement of esophageal pressure is a time-honored practice in studies of critically ill patients, including those of the prone position $(14,25)$.

\section{Conclusion}

Our findings suggest that combining prone ventilation and cyclical sighs may provide optimal lung recruitment in the early stage of ALI/ARDS because they act through complementary mechanisms. Combining these two strategies may result in a significant increase of the $\mathrm{Pa}_{\mathrm{O}_{2}}$ or may allow maintenance of an acceptable $\mathrm{Pa}_{\mathrm{O}_{2}}$ at a lower tidal volume and/or PEEP, thus potentially limiting VILI. Further studies are required to characterize those patients who can be predicted to benefit from the combined use of prone ventilation and sighs.

Acknowledgment: The authors thank the physicians and nurses of the "Emma Vecla" Intensive Care Unit of the Ospedale Policlinico di Milano for their precious help and cooperation. They also thank Dr. Paolo Cadringher for his technical support and Dr. Angelo Colombo for his revision and advice in the statistical analysis.

\section{References}

1. The Acute Respiratory Distress Syndrome Network 2000. Ventilation with lower tidal volume as compared with traditional tidal volume for acute lung injury and the acute respiratory distress syndrome. $N$ Engl J Med 2000;342:1301-1308.

2. Bendixen H, Hedley-White J, Laver M. Impaired oxygenation in surgical patients during general anesthesia with controlled ventilation: a concept of atelectasis. N Engl J Med 1963;269:1991-1996.

3. Richard J, Maggiore S, Jonson B, Mancebo J, Lemaire F, Brochard L. Influence of tidal volume on alveolar recruitment: respective role of PEEP and a recruitment maneuver. Am J Respir Crit Care Med 2001; 163:1609-1613.

4. Amato M, Barbas C, Medeiros D, Magaldi R, Schettino G, Lorenzi-
Filho G, Kairalla R, Deheinzelin D, Munoz C, Oliveira R, et al. Effect of a protective ventilation strategy on mortality in the acute respiratory distress syndrome. N Engl J Med 1998;338:347-354.

5. Pelosi P, Cadringher P, Bottino N, Panigada M, Carrieri F, Riva E, Lissoni A, Gattinoni L. Sigh in acute respiratory distress syndrome. Am J Respir Crit Care Med 1999;159:872-880.

6. Villagra A, Ochagavia A, Vatua S, Murias G, Del Mar Fernandez M, Lopez Aguilar J, Fernandez R, Blanch L. Recruitment maneuvers during lung protective ventilation in acute respiratory distress syndrome. Am J Respir Crit Care Med 2002;165:165-170.

7. Grasso S, Mascia L, Del Turco M, Malacarne P, Giunta F, Brochard L, Slutsky A, Ranieri V. Effects of recruiting maneuvers in patients with acute respiratory distress syndrome ventilated with protective ventilatory strategy. Anesthesiology 2002;96:795-802.

8. Van der Kloot T, Blanch L, Youngblood A, Weinert C, Adams A, Marini J, Shapiro R, Nahum A. Recruitment maneuvers in three experimental models of acute lung injury: effect on lung volume and gas exchange. Am J Respir Crit Care Med 2000;161:1485-1494.

9. Mancini M, Zavala E, Mancebo J, Fernandez C, Barbera J, Rossi A, Roca J, Rodriguez-Roisin R. Mechanisms of pulmonary gas exchange improvement during a protective ventilatory strategy in acute respiratory distress syndrome. Am J Respir Crit Care Med 2001;164:14481453.

10. Gattinoni L, Pesenti A, Avalli L, Rossi F, Bombino M. Pressure-volume curve of total respiratory system in acute respiratory failure. Computed tomographic scan study. Am Rev Respir Dis 1987;136:730-736.

11. Gattinoni L, Pesenti A, Bombino M, Baglioni S, Rivolta M, Rossi F, Rossi G, Fumagalli R, Marcolin M, Mascheroni D, et al. Relationships between lung computed tomography density, gas exchange and PEEP in acute respiratory failure. Anesthesiology 1988;69:824-832.

12. Gattinoni L, Pelosi P, Vitale G, Pesenti A, D'Andrea L, Mascheroni D. Body position changes redistribute lung computed-tomographic density in patients with acute respiratory failure. Anesthesiology 1991; 74:15-23.

13. Chatte G, Sab J-M, Dubois J-M, Sirodot M, Gaussorgues P, Robert D. Prone position in mechanically ventilated patients with severe acute respiratory failure. Am J Respir Crit Care Med 1997;155:473-478.

14. Pelosi P, Tubiolo D, Mascheroni D, Vicardi P, Crotti S, Valenza F, Gattinoni L. Effects of the prone position on respiratory mechanics and gas exchange during acute lung injury. Am J Respir Crit Care Med 1998;157:387-393.

15. Gattinoni L, Tognoni G, Pesenti A, Taccone P, Mascheroni D, Labarta V, Malacrida R, Di Giulio P, Fumagalli R, Pelosi P, et al. Effect of prone positioning on the survival of patients with acute respiratory failure. N Engl J Med 2001;345:568-573.

16. Cakar N, Van der Kloot T, Youngblood A, Adams A, Nahum A. Oxygenation response to a recruitment maneuver during supine and prone positions in oleic acid-induced lung injury model. Am J Respir Crit Care Med 2000;161:1949-1956.

17. Bernard G, Artigas A, Brigham K, Carlet J, Falke K, Hudson L, Lamy M, Legall J, Morris A, Spragg R. The American-European Consensus Conference on ARDS: Definitions, mechanisms, relevant outcomes, and clinical trial coordination. Am J Respir Crit Care Med 1994;149: 818-824.

18. Damia G, Mascheroni D, Croci M, Tarenzi L. Perioperative changes in functional residual capacity in morbidly obese patients. Br J Anaesth 1988;60:574-578.

19. Hubmayr R, Walters B, Chevalier P, Rodarte J, Olson L. Topographical distribution of regional lung volume in anesthetized dogs. $J$ Appl Physiol 1983;54:1048-1056.

20. Yang Q-H, Kaplowitz M, Lai-Fook S. Regional variations in lung expansion in rabbits: prone vs. supine position. J Appl Physiol 1989;67:13711376.

21. Patroniti N, Foti G, Cortinovis B, Maggioni E, Bigatello L, Cereda M, Pesenti A. Sigh improves gas exchange and lung volume in patients with acute respiratory distress syndrome undergoing pressure support ventilation. Anesthesiology 2002;96:788-794.

22. Ranieri VM, Brienza N, Santostasi S, Puntillo F, Mascia L, Vitale N, Giuliani R, Memeo V, Bruno F, Fiore T, et al. Impairment of lung and chest wall mechanics in patients with acute respiratory distress syndrome: role of abdominal distension. Am J Respir Crit Care Med 1997;156:1082-1091.

23. Gattinoni L, Pelosi P, Suter P, Pedoto A, Vercesi P, Lissoni A. Acute respiratory distress syndrome caused by pulmonary and extrapulmonary disease: different syndromes? Am J Respir Crit Care Med 1998;158: $3-11$.

24. Gattinoni L, Caironi P, Pelosi P, Goodman L. What has computed tomog- 
raphy taught us about the acute respiratory distress syndrome? Am J Respir Crit Care Med 2001;164:1701-1711.

25. Guerin C, Badet M, Rosselli S, Heyer L, Sab J-M, Langevin B, Philit F, Fournier G, Robert D. Effects of prone position on alveolar recruitment and oxygenation in acute lung injury. Intensive Care Med 1999; 25:1222-1230.

26. Numa A, Hammer J, Newth J. Effect of prone and supine positions on functional residual capacity, oxygenation and respiratory mechanics in ventilated infants and children. Am J Respir Crit Care Med 1997; 156:1185-1189.

27. Gattinoni L, D'Andrea L, Pelosi P, Vitale G, Pesenti A, Fumagalli R. Regional effects and mechanism of positive end-expiratory pressure in early adult respiratory distress syndrome. JAMA 1993;269:2122-2127.
28. Gattinoni L, Pelosi P, Crotti S, Valenza F. Effects of positive end-expiratory pressure on regional distribution of tidal volume and recruitment in adult respiratory distress syndrome. Am J Respir Crit Care Med 1995; 151:1807-1814.

29. Pelosi P, Goldner M, McKibben A, Adams A, Eccher G, Caironi P, Losappio S, Gattinoni L, Marini J. Recruitment and derecruitment during acute respiratory failure. Am J Respir Crit Care Med 2001;164: 122-130.

30. Esteban A, Anzueto A, Frutos F, Alia I, Brochard L, Stewart T, Benito S, Epstein S, Apezteguia C, Arroliga A, et al. Characteristics and outcomes in adult patients receiving mechanical ventilation. JAMA 2002;287:345-355.

31. Milic-Emili J, Henderson J, Dolovich M, Trop D, Kaneko K. Regional distribution of inspired gas in the lung. J Appl Physiol 1966;21:749-759. 